\title{
Antropología, desarrollo e interculturalidad: propuestas desde América Latina
}

\section{Anthropology, Development and Interculturalism: Proposals from Latin America}

\author{
Almudena CORTÉS MAISONAVE \\ Universidad Complutense de Madrid \\ almudena.cortes@cps.ucm.es
}

Recibido: 22 de agosto de 2014

Aceptado: 2 de septiembre de 2014

\section{Resumen}

Este texto que introduce el monográfico recoge y plantea las aportaciones que la antropología social ha realizado desde América Latina en el análisis del desarrollo y la interculturalidad. El interés de esta tarea es doble. Por una parte, América Latina ha sido un laboratorio geopolítico privilegiado en la puesta en marcha de programas y proyectos de desarrollo, que se han exportado a otros lugares del planeta. Por otra parte, las contribuciones realizadas por la antropología latinoamericana han constituido importantes hitos en el estudio del desarrollo y la interculturalidad. Sin ánimo de ser exhaustivos, los artículos que forman parte de este monográfico dan buena cuenta de ello, y se centran en los debates en torno al desarrollo, en el papel de la Ayuda Oficial al Desarrollo y de las Organizaciones No Gubernamentales en América Latina, o por ejemplo, en las consecuencias de las propuestas sobre interculturalidad y etnodesarrollo realizadas en la región.

Palabras clave: Antropología Social; Etnografía; Desarrollo; Interculturalidad; América Latina.

\begin{abstract}
This text that introduces the monograph presents the contributions that social anthropology has made in the analysis of development and interculturalism from Latin America. The interest of this work is twofold. On the one hand, Latin America has been a privileged geopolitical laboratory where programs and projects were fostered and exported to other parts of the world. Moreover, the contributions made by Latin American anthropology have been important milestones in the study of development and interculturalism. Without being exhaustive, the articles included in this special issue give a good account of it, and focus on debates around development, the role of ODA and NGOs in Latin America, or for example, the consequences of interculturalism and ethnic development proposals made in the region.
\end{abstract}

Keywords: SocialAnthropology; Ethonograpy; Development; Interculturality; Latin America.

Referencia normalizada: Cortés Maisonave, A. (2014). Antropología, desarrollo e interculturalidad: perspectivas desde América Latina. Revista de Antropología Social, 23, pp. 9-28. 
SUMARIO: 1. Introducción. 2. Desarrollo, Modernidad y Colonialidad. 3. La Ayuda Oficial al Desarrollo y las Políticas de Cooperación para el Desarrollo. 4. El papel de las ONGs en la reflexión antropológica. 5. Interculturalidad y Etnodesarrollo. 6. Presentación del monográfico. 7. Referencias bibliográficas.

\section{Introducción}

El objetivo del texto que el/ la lector/a tiene entre sus manos es presentar el volumen monográfico dedicado a las relaciones entre "Antropología, desarrollo e interculturalidad: propuestas desde América Latina”. Se va a entender por desarrollo una construcción histórica, política, social, económica y cultural, lo que va a permitir situar los debates sobre el desarrollo y sus consecuencias desde una perspectiva crítica y problematizadora sobre las condiciones geopolíticas del conocimiento generado sobre el desarrollo ${ }^{1}$. En este sentido, este número sitúa el análisis del desarrollo como una práctica de poder en diferentes esferas institucionales, sociales, epistemológicas o políticas, tal y como han señalado los precursores de la Red de Antropologías del Mundo-World Anthropologies Network (Lins Ribeiro y Escobar, 2008).

La antropología ha generado debates, análisis y perspectivas pioneras a la hora de entender la relación entre "desarrollo" y diversidad cultural y/ o étnica, y ha contribuido a generar propuestas como la de la interculturalidad, entre otras. Y en este proceso, América Latina ha sido un espacio geopolítico especialmente fructífero desde y sobre el cual se han planteado debates pioneros y se han realizado importantes aportes etnográficos, algunos de los cuales recogemos en este número monográfico. En este sentido, al proponer un monográfico sobre antropología, desarrollo e interculturalidad en y desde América Latina, hemos situado las discusiones en un marco de análisis caracterizado por los debates del proyecto Modernidad/Colonialidad $^{2}$ protagonizado e impulsado por autores/as que o bien son latinoamericanos/ as o trabajan sobre Latinoamérica desde las Ciencias Sociales y Humanidades. Pero también, hemos prestado especial atención al papel que ha desempeñado el desarrollo canalizado a través de las políticas de la Ayuda Oficial al Desarrollo (en adelante AOD), como una forma de extender formas políticas y representaciones culturales en torno al Estado moderno. Esto se conecta directamente con uno de sus actores fundamentales, las Organizaciones No Gubernamentales (en adelante ONGs), y su papel

${ }^{1}$ El desarrollo se ha convertido en un dispositivo de poder y de saber, y por ese motivo es necesario prestar atención a las condiciones geopolíticas en las que el desarrollo mismo surge.

${ }^{2}$ El pensamiento decolonial ha sido impulsado por el Proyecto Modernidad/ Decolonialidad, uno de los más importantes colectivos de pensamiento crítico activos en América Latina durante la primera década del siglo XXI. Se trata de una red multidisciplinar y multigeneracional de intelectuales entre los cuales se contaban los sociólogos Aníbal Quijano, Edgardo Lander, Ramón Grosfoguel y Agustín Lao-Montes, los semiólogos Walter Mignolo y Zulma Palermo, la pedagoga Catherine Walsh, los antropólogos Arturo Escobar y Fernando Coronil, el crítico literario Javier Sanjinés y los filósofos Enrique Dussel, Santiago Castro-Gómez, María Lugones y Nelson Maldonado-Torres. Sus trabajos pueden ser vistos como el más genuino aporte latinoamericano al Poscolonialismo, que generalmente estuvo dominado por autores provenientes de las antiguas colonias inglesas o francesas en Asia, Oceanía y Oriente Medio. 
llevado a cabo en la industria del desarrollo. Por último, el análisis sobre desarrollo e interculturalidad que da cuerpo a los artículos de este monográfico persigue mostrar las perspectivas autóctonas planteadas desde Latinoamérica, como una forma determinada de entender las relaciones étnicas al interior de la sociedad, así como una propuesta política e ideológica que cuestiona y plantea alternativas a los diseños coloniales, y aspira a transformar las políticas públicas y la misma concepción de Estado.

\section{Desarrollo, Modernidad y Colonialidad}

El término "desarrollo" forma parte del proyecto de la Modernidad, y la Modernidad constituye un proyecto occidental que empieza a expandirse a partir de la conquista de América. La Modernidad es una categoría compleja que se refiere, al mismo tiempo, a una forma de organización social, a un sistema de representaciones culturales que intenta extender y que conlleva distintas formas de racionalidad, de valores, de concepciones del tiempo y el espacio ${ }^{3}$, y a un periodo histórico concreto, aparte de referirse también a las nociones de novedad y de contemporaneidad. Situar temporalmente el periodo moderno resulta bastante problemático, pudiendo ubicarse su inicio en cualquier momento de principios del siglo XVI hasta mediados del siglo XIX. La "Colonialidad" hace referencia a la "lógica cultural" del colonialismo, es decir al tipo de herencias coloniales que persisten y se multiplican incluso una vez que el colonialismo ha finalizado. Se dice entonces que en América Latina el colonialismo finalizó en el siglo XIX (en África y Asia lo hizo apenas en el siglo XX) pero no la colonialidad, que persiste hasta el día de hoy. La Modernidad es, pues, la cara visible de la colonialidad, y no puede existir la primera sin la segunda (Mignolo, 2003). Como proyecto ilustrado que "desea" traer progreso, orden y razón al mundo entero, la universalización de la Modernidad impuso su forma de organización social, definida en parte por sus instituciones —el Estado-nación, los aparatos administrativos modernos, la expansión del mercado, la ciencia y la tecnología - . En este sentido, en América Latina la Modernidad ha dejado su legado a partir de una serie de herencias coloniales: el racismo, el eurocentrismo epistémico y la occidentalización de los estilos de vida. Estas herencias corresponderían a tres categorías centrales: la colonialidad del poder, la colonialidad del saber y la colonialidad del ser.

La ideología del desarrollo se ha propagado por el mundo gracias a la lógica de expansión "de los distintos diseños globales que a lo largo de cinco siglos justificaron e implementaron la "colonialidad del poder", "del saber" y "del ser" desde la conquista de América. La Cristianización del mundo fue el primero. Le siguió la Misión Civilizadora, la ‘civilización’ secular del mundo. A este diseño siguió el

${ }^{3}$ En cuanto a la concepción del tiempo y el espacio, Giddens (1993) enfatiza que la Modernidad conlleva la descontextualización, que es el despegar, arrancar la vida local de su contexto, y que la vida local cada vez más, es producida desde lo translocal. En las sociedades tradicionales, el espacio y el lugar (localidad) coinciden en buena medida, situación que cambia cuando la Modernidad separa el espacio del lugar, posibilitando las relaciones a distancia entre personas que no están unidas y presentes en una localidad. 
Desarrollo y Modernización, entre 1945 y 1950 aproximadamente" (Castro Gómez, 2007; Grosfoguel, 2006; Maldonado Torres, 2007; Mignolo, 2002 y 2003; Quijano, 2000a y 2000b; Walsh 2003, 2005 y 2006). El desarrollo, por tanto, es un concepto que se configura en el seno de la cultura occidental industrializada, sobre todo a partir de los años cincuenta tras la Segunda Guerra Mundial. El término empezó a adquirir relevancia política a partir del discurso del presidente Truman el 20 de enero de 1949, que basaba el desarrollo en industrialización y urbanización, tecnificación de la agricultura, rápido crecimiento de la producción material y los niveles de vida, y adopción generalizada de la educación y los valores culturales modernos. Escobar sostiene que más allá de los calificativos que lo han acompañado, —endógeno, sostenible, autodirigido, económico, social, participativo, etc.,- en realidad se habla del desarrollo sin cuestionar su estatus ontológico (Escobar, 1997:5). Este autor considera que la expansión del Desarrollo, entendida tras la Segunda Guerra Mundial como el proceso dirigido para reproducir en la mayor parte de Asia, África y América Latina las condiciones que se suponía que caracterizaban a las naciones económicamente más avanzadas del mundo, ha tenido y sigue teniendo consecuencias negativas para los países que son considerados subdesarrollados. En este punto, colonialidad y desarrollo se conectan. La colonialidad consiste en un proceso múltiple de poder que se funda en la "imposición de una clasificación racial/étnica de la población del mundo como piedra angular de dicho patrón de poder, y opera en cada uno de los planos, ámbitos y dimensiones, materiales y subjetivas, de la existencia social cotidiana y a escala societal" (Quijano, 2000a: 342). En este contexto, una de las consecuencias más significativas del desarrollo ha sido que actúa como un mecanismo de negación de la diferencia: que transmite pautas y valores ajenos a sus propios desarrollos históricos.

Tal y como señala Esteva: "El subdesarrollo comenzó el 20 de enero de 1949. Ese día, dos mil millones de personas se volvieron subdesarrolladas. En realidad, desde entonces dejaron de ser lo que eran, en toda su diversidad, y se convirtieron en un espejo invertido de la realidad de otros" (Esteva, 1996: 53). Insistiendo en esa idea, Rist plantea que "a partir de 1949, más de dos mil millones de habitantes del planeta van — las más de las veces sin saberlo — a cambiar de nombre (...): ya no serán africanos, latinoamericanos o asiáticos (por no decir bambaras, shona, bereberes, quechuas, aymaras, balineses o mongoles), sino simplemente subdesarrollados" (Rist, 2002). Es posible decir entonces que el desarrollo constituye un proyecto claramente moderno.

De esta forma encontramos que el término "desarrollo" está presente en muy distintos niveles de la realidad cotidiana y ha sido interiorizado muy fácilmente en el mundo occidental, ya que tal y como apunta Escobar, la cuestión clave es que el desarrollo se ha convertido en una certeza en el imaginario social, la realidad ha sido colonizada por el discurso del desarrollo (Escobar, 1996; 2012). Sin embargo, ha sido considerado problemático por diversos autores en la economía, la sociología y la antropología. Sus aportaciones cuestionan precisamente el concepto de desarrollo porque sostienen que tanto el propio concepto, como el lenguaje ligado al mismo, no son neutrales. 
Tal y como señala Marín, el desarrollo presenta una dificultad metodológica intrínseca: siempre sugiere algo positivo (Marín, 2004). Esteva sostiene que esta connotación positiva inherente al término es consecuencia de la transferencia del término "desarrollo" de la esfera biológica a la social en el último tercio del siglo XVIII. De tal forma que el significado que tiene el desarrollo en el campo de la biología, ha permanecido presente a lo largo de la historia, y se alude siempre a él independientemente de los calificativos que se le añadan. En su esencia, siempre subyace una connotación positiva, porque se trata de "un proceso de cambio positivo y universal" (Esteva, 1996: 54). Efectivamente, otros autores como Sampedro y Berzosa, han planteado que este término resulta esperanzador y que "mientras que la riqueza evoca un Estado cuajado allá en lo alto, lejos de la pobreza, en cambio "desarrollo" sugiere la supresión de la distancia, al aludir a un proceso que arrancaría de la pobreza misma y vendría a ser, en conclusión, la escalera por donde se sube a la riqueza (Sampedro y Berzosa, 1996: 17). El desarrollo, por tanto, no es neutral al encerrar un significado positivo y natural, lo que se deriva del hecho de que es una construcción social e histórica.

Desde la antropología se ha cuestionado la forma de construir el desarrollo como certeza en el imaginario social, y como concepto "aséptico" en cuanto a una categoría entrecruzada por relaciones de poder. Sin embargo, éste ha sido construido como una categoría capaz de producir unas formas de existencia que se ajusten a los proyectos de modernización. Se trataría de la producción sistemática de una ontología social urbana, de unas formas de ser-en-el-mundo en la que los sujetos son "sujetados" al capitalismo. El desarrollo sería así una categoría que en lugar de oprimir, sería algo que se desea, pues produciría las condiciones materiales e inmateriales de existencia para amplios sectores de la población.

Desde el punto de vista epistemológico, el desarrollo se insertaría en la lógica de expansión colonial europea en América Latina que busca la imposición de una sola forma válida de producir conocimientos, tenida ahora como universal. Con el inicio del colonialismo en América comienza no sólo la organización colonial del mundo sino, simultáneamente, "la constitución colonial de los saberes, de los lenguajes, de la memoria y del imaginario". Se da inicio al largo proceso que culminará en los siglos XVIII y XIX en el cual, por primera vez, se organiza la totalidad del espacio y del tiempo - todas las culturas, pueblos y territorios del planeta, presentes y pasados - en una gran narrativa universal. En esta narrativa, Europa es —o ha sido siempre - simultáneamente el centro geográfico y la culminación del movimiento temporal. En este período moderno temprano/colonial, se dan los primeros pasos en la "articulación de las diferencias culturales en jerarquías cronológicas" y de lo que Johannes Fabian llama la negación de la simultaneidad (Fabian, 1983). Con los cronistas españoles se da inicio a la "masiva formación discursiva" de construcción de Europa/Occidente y lo otro, del europeo y el indio, desde la posición privilegiada del lugar de enunciación asociado al poder imperial. En este esquema, todos los conocimientos que no se ajusten a las reglas universales de la "episteme" dominante son vistos como "pre-científicos". Edgardo Lander muestra cómo este modelo es adoptado por las ciencias sociales 
del siglo XX, que empiezan a adoptar unos lenguajes y una concepción específica del mundo social (marcada sobre todo por las ciencias económicas) que se institucionaliza en los proyectos de desarrollo en los años sesenta y setenta en toda América Latina (Lander, 2000).

\section{La Ayuda Oficial al Desarrollo y las Políticas de Cooperación para el Desarrollo}

Lo particular del concepto de desarrollo es que se vincula con el término de "ayuda" y de "cooperación", y tenemos que entenderlo como acciones de desarrollo en otros países. En la actualidad se entiende por Ayuda Oficial al Desarrollo (AOD) los créditos, donaciones en especie y dinero, y asistencia técnica que gobiernos de países desarrollados, organizaciones multilaterales y Organizaciones No Gubernamentales (ONGs) transfieren a otros países con el objetivo de promover su crecimiento económico, mejorar las condiciones de vida de sus habitantes o promover cambios institucionales.

Como parte del diseño surgido en la Modernidad, la Ayuda Internacional surge tras la Segunda Guerra Mundial, para lograr la cohesión dentro de los bloques en la Guerra Fría, y se convertiría en un instrumento para expandir o preservar mercados y zonas de influencia política en los países que accedían a la independencia tras la descolonización (Robertson, 1984). Autoras como Gronemeyer han visto en el Plan Marshall el primer ejemplo de ayuda moderna. La autora, que realiza una revisión histórica del concepto de ayuda, distingue entre un concepto tradicional de ayuda y un concepto moderno de ayuda que empezó a gestarse en el siglo XVIII. Mientras que el concepto tradicional alude a la incondicionalidad y se concibe más como un gesto de caridad que se justifica por motivos religiosos, el concepto moderno de ayuda responde a una necesidad diagnosticada desde fuera, más que a un "grito de ayuda". La autora considera que la ayuda actual es "ayuda prestada al proceso de modernización" y su impulso esencial es superar un déficit diagnosticado desde fuera (Gronemeyer, 1996: 21).

En este sentido, la AOD es un elemento del nuevo orden internacional que se configuró tras la Segunda Guerra, y una fuerza en la configuración de las estructuras estatales en los Países Receptores de Ayuda (PRA). Como parte del propio discurso estatal, la idea central y mayoritaria es que todos los Estados en principio son o llegarán a ser, similares o mutuamente inteligibles, reconocibles por los otros Estados en sus estructuras y en sus racionalidades al gobernar sus acciones. Dicha comprensión ahistórica del Estado fue asumida por las élites políticas nacionalistas en el mundo poscolonial, ansiosas de transformar sus Estados en Estados nacionales "normales". Así, una forma de producir "Estados normales" fue desempeñada por agencias de desarrollo, donantes internacionales y el impulso de la teoría del desarrollo, lo que hizo que el Estado fuera visto como un agente de modernización, una isla de Modernidad y racionalidad, una parte de lo que se ha denominado sector moderno (Hansen y Stepputat, 2001: 10-11). Hoy las ONGs y las agencias de ayuda internacional han emergido como los principales transmisores de nuevas tecnologías administrativas en el campo del desarrollo. Por lo tanto, el desarrollo también forma 
parte de los lenguajes de gobierno; forma parte de las estrategias de modernización emprendidas por el Estado.

El punto nodal consiste en entender que la asistencia internacional ha operado como un canal a través del cual los Estados más poderosos en el sistema internacional, los países donantes, influyeron sobre el proceso de cambio o modernización de las regiones y países deprimidos del planeta por medio de la institucionalización de un conjunto de normas y principios que determinaron el comportamiento interno e internacional de dichos Estados. La AOD ha actuado como un mecanismo de difusión y aplicación de dichos principios y normas que, al haberse difundido por los PRA, aseguran una cierta vinculación de sus Estados al sistema internacional. En otras palabras, la AOD actuó como una fuerza integradora y estabilizadora del sistema internacional que conectó las conductas de los Estados de los PRA a un orden internacional en proceso de formación.

Así, por ejemplo, entre 1950 y 1970 la AOD dirigió sus esfuerzos a la formación de capital en las economías de los PRA por medio de la consolidación y diversificación de las inversiones gubernamentales. Para ello debieron establecerse en cada país receptor, estructuras de planificación, manejo presupuestario y programación dentro de un modelo centralizado, a partir del crecimiento de un sector para-estatal. Desde 1982, la reforma estatal promovida desde la AOD, dirigida a lograr la liberalización y desregulación de la economía y del desarrollo humano, potenció, por el contrario, la consolidación de un Estado desarrollista descentralizado, abierto a la participación de la sociedad en la toma de decisiones.

En ambas coyunturas (1950-1970 y 1982-presente), los flujos de AOD han conducido a la formación de una forma de Estado en los PRA, denominado "desarro1lista" (Montúfar, 2002: 37 y ss). Según este autor, el Estado desarrollista puede ser definido como un tipo de Estado cuyo objetivo principal es intervenir en la economía y sociedad para producir un determinado patrón de modernización. Este tipo de modernización no es neutral, y está encaminada a asegurar, mediante un proceso de homogeneización institucional y convergencia de políticas alrededor del paradigma del desarrollo, el que estos Estados se vinculen al sistema internacional que surgió en la posguerra. El patrón de intervención de este tipo de Estado se basa en su capacidad de inversión, la cual, según el paradigma, se dirigió a la formación de capital físico (entre 1950 y 1970) o al capital humano (desde los noventa). El patrón de inversión estatal definió varias tendencias de expansión burocrática: centralizadoras o descentralizadoras; concentradoras de la toma de decisiones o participativas; basadas en esquemas regulatorios rígidos o de desregulación; la intervención en los precios o la liberalización de los mismos, etc.

En 1994 se publicó el informe "La dimensión política del desarrollo humano" (Montúfar, 2002: 213), en el cual la noción de gobernabilidad fue planteada. La dimensión política sugirió cambios que fortalecieron la descentralización, el apoyo a los poderes locales, el aumento de la participación y la transparencia. Se lograría una nueva cultura política basada en el consenso y la creación de un ambiente de tolerancia. Esto significaba en la práctica que el Estado debía cambiar su patrón de intervención desde un carácter redistributivo y movilizador de recursos hacia uno 
más asociativo y centrado en el apoyo de las iniciativas privadas. La participación directa del Estado en la economía debería reducirse al mínimo, fortaleciendo sus funciones de regulación y control (Montúfar, 2002: 216). Y en este proceso, la cooperación al desarrollo desempeñó un rol estratégico reforzado a través del papel de las ONGs.

\section{El papel de las ONGs y la reflexión antropológica}

A partir de los años noventa, tuvo lugar una explosión de Organizaciones No Gubernamentales (ONGs) en el Tercer Sector, que actúan como mediadores entre la sociedad civil y los financiadores del desarrollo. Las poblaciones locales tampoco son ajenas a los procesos de desarrollo, ya que llevan décadas de experiencia ante la circulación de estos discursos, y los han adaptado, asimilado, o resistido, generando sus propios discursos y alternativas. Algunas de ellas han organizado sus luchas en ONGs, pero también formando movimientos sociales para insertar sus demandas de tierra, ciudadanía, respeto a la alteridad y autonomía en las políticas de desarrollo (Gimeno y Monreal, 1999).

Tal y como se ha señalado recientemente, la presencia de las ONGs puede estar condicionando de distintas maneras el trabajo de los/as antropólogos/ as. Este condicionamiento se inserta en el tema epistemológico fundacional de la antropología que es la relación entre sujeto que estudia y objeto estudiado (Bretón, López Bargados y Roca, 2005: 9). En este sentido, es necesario mostrar las contradicciones de la propia práctica de estas organizaciones. Las ONGs se han convertido en uno de los principales mecanismos establecidos por los expertos para generar riqueza en los países pobres. Esta función y esta expectativa las empuja cada vez más a interaccionar preferentemente con los elementos más dinámicos de estas sociedades. Pero al mismo tiempo, dirigen sus actividades hacia la prestación de servicios a los colectivos sociales más desfavorecidos, que no suelen coincidir con los mencionados "elementos más dinámicos". Vemos, por tanto, cómo las ONGs estarían ocupando un espacio intermedio entre los elementos más dinámicos y los sectores más pobres.

Unido a lo anterior, tal y como hemos visto para el caso español, el porcentaje público de la financiación de las ONGs suele sobrepasar con mucho el 50\% de su presupuesto. La cuestión clave estribaría en ver hasta qué punto las ONGs son tan independientes del sector público como señalan y cómo se define lo de "sin ánimo de lucro". Se presupone que son más flexibles, que tienen más capacidad para ejercer como interlocutores horizontales con las organizaciones de beneficiarios, que son más eficaces en términos de los resultados y que son más eficientes, pues un mayor porcentaje de los recursos invertidos irían a parar directamente a los proyectos, dada la simplicidad burocrática de estas organizaciones.

No pocos analistas, incluyendo muchos antropólogos, constatan una relación directa entre la gran proliferación de ONGs y el apogeo de la retórica anti-estatalista del neoliberalismo. No debe olvidarse que las ONGs no empezaron a tener el protagonismo internacional con que cuentan, "hasta el momento en que el Banco Mundial decidió convocarlas en 1982 para estudiar el papel que deberían desempeñar en el contexto de la política neoliberal que se iba a aplicar, a escala global, en los 
años siguientes y que afectaría a la mayor parte de los países (Picas, 2001:180). La búsqueda de un ajuste con rostro humano a finales de los noventa (el Post-Consenso de Washington) ha fortalecido aún más el rol a desempeñar por las ONGs. Se encuentran robustecidas en una tesitura en que los discursos al uso enfatizan el papel de la sociedad civil y del capital social en las políticas de desarrollo y de gestión y atención de la migración.

La eclosión de las ONGs y su consiguiente irrupción en el universo de las etnografías, ha tenido consecuencias metodológicas, logísticas e incluso identitarias importantes para la antropología. En primer lugar, ha contribuido a desdibujar aún más el supuesto objeto de estudio específico de la disciplina; difuminación que remite a una aproximación pluridisciplinar y lleva a cuestionarse la propia aportación antropológica. Un elemento a tener muy en cuenta es que la proliferación de ONG ha generado nuevas posibilidades profesionales y logísticas a los antropólogos.

En las investigaciones etnográficas irrumpen inevitablemente los debates en torno al neocolonialismo, poscolonialismo, subalternidad, etc. El conjunto de contradicciones se acentúa enormemente cuando los antropólogos no se limitan a estudiar un contexto en el que se llevan a término determinados programas de desarrollo, sino que ellos mismos pasan a constituir parte de tales programas en la medida en que la investigación etnográfica recibe financiación, o en tanto que las mismas ONGs solicitan los servicios de tales profesionales.

En algunos aspectos, las ONGs han pasado a ocupar en el imaginario de la antropología - y en su praxis - el papel ambivalente tradicionalmente atribuido a los misioneros. Percibidas a menudo como vectores aculturadores, transmisores de los ejes dominantes en la economía y la cultura global, es comprensible la actitud de denuncia y de movilización en su contra que con frecuencia se esgrime entre los antropólogos. Pero los estos deben ser conscientes de esa eventual contradicción, de la influencia que esta denuncia y movilización puede ejercer sobre su propia investigación y asimismo de la parálisis que en ocasiones puede traer consigo. Quizás la contribución más valiosa de las ONGs a la antropología radique en que conforman un campo de pruebas nuevo, y particularmente desafiante, para una antropología comprometida (Gledhill, 2000; Harris, 2000).

\section{Interculturalidad y Etnodesarrollo}

Las críticas a la conceptualización hegemónica del desarrollo han tenido como resultado el surgimiento de debates que revisan este concepto. Tal y como señala Unceta (2009), las críticas dieron como resultado dos formas de entender el desarrollo: la reformista y la denominada como "postdesarrollo". La perspectiva reformista apostaba por una reforma del concepto de desarrollo en la que no se establecía de forma automática la relación entre crecimiento y bienestar, y trataba de introducir un mecanismo de redistribución de los recursos. Esta visión del desarrollo recogería las críticas y los fracasos del desarrollo, y los incorporaría a su modelo, de tal forma que se va a referir al desarrollo como la capacidad de agencia de los beneficiarios/as, así como el incremento de las oportunidades de las personas para vivir la vida que deseen. Se trata de la definición planteada por Amartya Sen en su obra 
Development as capability expansion, publicada en 1990 y que alcanzó un gran eco cuando recibió el Premio Nobel de Economía en 1998. Precisamente este es el enfoque se ha seguido en los organismos internacionales multilaterales, sobre todo en el Programa de Naciones Unidas para el Desarrollo (PNUD).

La perspectiva del postdesarrollo, partiría de la negación del concepto hegemónico del desarrollo, de tal manera que no habría espacio para reformar el concepto. El desarrollo constituiría una forma de entender la existencia humana basada en el productivismo, en el dominio sobre la naturaleza y en la defensa de la Modernidad occidental (Unceta, 2009). Esto solo ha sido posible apoyándose en un paradigma técnico-científico que ha desplazado cualquier otra forma de conocimiento. Los autores que defienden este posicionamiento teórico e ideológico, rechazan la manera en que la idea del desarrollo se ha ido extendiendo como promesa de emancipación por todo el mundo, para convertirse en algo obligatorio e indiscutible (Arturo Escobar, 1996; Gilbert Rist, 2002; Serge Latouche, 2007, entre otros). Es necesario señalar que para estos autores tanto el desarrollo como el subdesarrollo son nociones que tienen su origen en un mismo tipo de aproximación a la realidad, condicionada por una mirada occidental — y occidentalizadora — incapaz de comprender los valores de las distintas culturas y civilizaciones, y su aportación al bienestar de los seres humanos. Este proceso es posible porque la premisa del progreso y del desarrollo se ha asentado sobre la conceptualización de su universalidad construida a partir de la experiencia particular (o parroquial) de la historia europea, lo que la convierte en una universalidad radicalmente excluyente, ya que tal y como señala Aimé Césaire: "Es Occidente el que hace la etnografía de los otros, y no los otros los que hacen la etnografía de Occidente" (Césaire, 2006: 33). Ésta es una construcción eurocéntrica, que piensa y organiza a la totalidad del tiempo y del espacio, a toda la humanidad, a partir de su propia experiencia, colocando su especificidad histórico-cultural como patrón de referencia superior y universal. Pero es más que eso. Este metarrelato de la Modernidad es un dispositivo de conocimiento colonial e imperial en que se articula esa totalidad de pueblos. Como nos recuerda Edgardo Lander (2000), esta forma de organización y de ser de la sociedad, se transforma mediante este dispositivo colonizador del saber, en la forma "normal" del ser humano y de la sociedad. Las otras formas de ser, las otras formas de organización de la sociedad, las otras formas del saber, son trasformadas no sólo en diferentes, sino en carentes, en arcaicas, primitivas, tradicionales, premodernas. Son ubicadas en un momento anterior del desarrollo histórico de la humanidad, lo cual, dentro del imaginario del progreso, enfatiza su inferioridad. Este autor nos recuerda que las "sociedades occidentales modernas" se han erigido en el modo de vida al cual se llegaría naturalmente si no fuese por los obstáculos representados por composiciones raciales inadecuadas, culturas arcaicas o tradicionales, prejuicios mágico religiosos, o más recientemente, por los populismos y unos Estados excesivamente intervencionistas, como es el caso de Venezuela, Bolivia o Ecuador.

De esta forma, hay un número extenso de teóricos que no aparecen como parte del canon epistémico universal. A esta episteme unilateral Ramón Grosfoguel la denomina racista-sexista. Racista debido a que ningún hombre no occidental aparece en el canon y además inferioriza los conocimientos científico-sociales de otros sujetos, 
colocándose en un plano superior; sexista porque ninguna mujer, aparece en el canon. Esta estructura se ha convertido en un sentido común que se da por supuesto, se internaliza, y la elite trata de socializarla. De esta manera, la diversidad epistémica del mundo no aparece en el canon epistémico del desarrollo (Grosfoguel, 2006).

En este sentido, tal y como recoge y analiza el antropólogo Joan J. Pujadas, en los últimos veinticinco años en países latinoamericanos (concretamente Ecuador, Colombia, Brasil, Panamá o Argentina) ha habido significativos cambios legislativos o constitucionales que han proclamado el carácter pluricultural y plurilingüístico del Estado, redefiniendo el rol que los grupos y las culturas indígenas poseen en el marco del Estado-nación (Pujadas, 2011). Pero el mismo autor nos recuerda que a pesar de estas reformas legislativas, una cosa bien distinta es si se han podido aplicar ante la pervivencia de modelos culturales discriminatorios y/o asimilacionistas hacia los pueblos y nacionalidades indígenas, $\mathrm{y} / \mathrm{o}$ ante la ausencia de mecanismos políticos y jurídicos que aseguren la aplicación de esas reformas. Continua el autor recordando que tras doscientos años de independencia republicana, la relación entre las élites blanco-mestizas y las minorías indígenas se sigue caracterizando por una relación paternalista que interpreta y suplanta las voces de los indígenas, en un mecanismo que el antropólogo ecuatoriano Andrés Guerrero ha denominado "ventriloquía" (Guerrero, 2000; 2010).

Frente a estas interpretaciones hegemónicas de las relaciones culturales, desde América Latina se han realizado propuestas que tratan de subvertir estas relaciones marcadas por la colonialidad del conocimiento/poder y la narrativa de la historia que lo sostiene. Emergiendo en los años setenta a partir de discusiones sobre programas de educación bilingüe en Perú, Ecuador y Bolivia, la interculturalidad — de nuevo como el mestizaje - es una noción altamente heteroglósica. La encontramos sobre todo muy presente en el marco de la educación bilingüe — Kichwa y español-

Uno de los ejemplos que han servido de referencia para la región andina, y para América Latina en general, ha sido la propuesta intercultural planteada desde Ecuador. En este sentido, en Ecuador "construir la interculturalidad ha sido, desde inicios de los noventa, un principio político e ideológico del movimiento indígena ecuatoriano, principio que articula las demandas que estos plantean frente a un Estado monocultural para transformar las políticas públicas y la misma concepción de Estado" (Walsh, 2002: 115). Entonces, el gran reto de la interculturalidad es convertirse en una nueva relación social que, junto con los feminismos, ambientalismos y movimientos indígenas, pueda confrontar las antiguas jerarquías sociales de la razón, la propiedad, el género y la sexualidad para producir un Estado democrático.

En este sentido Xinia Zúñiga (2011) señala que la interculturalidad también debe ser entendida desde la experiencia de los pueblos indígenas, tal y como ha plasmado en su trayectoria la Universidad Intercultural Indígena Amawtay Wasi del Ecuador. Según su antiguo rector, Fernando Sarango, la interculturalidad ha implicado cuatro procesos históricos:

- Una interculturalidad subordinada: es la que han vivido los pueblos indígenas en los últimos 500 años, entendida como relación entre culturas en 
la que se establece la diferencia colonial entre unos y otros, indígenas y no indígenas.

- la interculturalidad institucionalizada, que es aquella que se establece a nivel de leyes - como respeto de las diferencias - pero no se acata en la práctica, expresando el doble discurso de la Modernidad

- la interculturalidad folklórica que se promueve en el contexto comercial, exotizando y utilizando los rasgos de las culturas originarias para agregar valor a bienes y servicios; es la exhibición de los trajes, la cocina, las lenguas.

- Finalmente, la interculturalidad implementada como reconocimiento de plurinacionalidad, es decir, como producto de la autodeterminación en una relación compleja de unidad en la diversidad dentro de un territorio estatal. Esta es, según Sarango, la interculturalidad con equidad. Este tipo de interculturalidad se encuentra todavía a la espera de su ejecución, y todavía se encuentra en una etapa de utopía.

El Estado republicano, liberal, colonial y nacional en América Latina ha impulsado históricamente la interculturalidad subordinada y folklórica, y últimamente también la institucionalizada, mediante el doble discurso de los derechos.

Por todo esto, la interculturalidad es una tecnología de creación del Estado y un lugar epistemológico para la producción de un tipo diferente de conocimiento. Reestructurar el antiguo Estado implica recordar el consenso liberal que lo sustentó, y el orden social que éste mantuvo basado en jerarquías coloniales de civilización e ingreso, y por tanto, desarrollo.

A partir de estos debates centrados en la propuesta de la interculturalidad, han surgido otras formas de entender el desarrollo, bajo el concepto de etnodesarrollo. Tras haber dedicado varias décadas del siglo XX (1910 a 1970) a acompañar y legitimar las políticas indigenistas diseñadas por los distintos Estados latinoamericanos, la antropología y los/ as antropólogos/as experimentan un viraje hacia lo que el antropólogo español radicado en Perú, Manuel Marzal (1998) ha denominado "Indigenismo crítico". Nos estamos refiriendo a la corriente de pensamiento que surge en la antropología mexicana y peruana en la década de los setenta "que cuestiona el indigenismo oficial de los gobiernos que trataban de integrar al indio a la nación mestiza" (Marzal, 1998: 184). A partir de este momento, varios antropólogos latinoamericanos (Bonfil, 1978; Ribeiro, 1977; o Varese, 1971), van a inaugurar otro tipo de relación entre antropología y etnicidad en América Latina, más preocupada en asesorar a los pueblos indígenas sobre los conocimientos sobre ellos y sobre la "sociedad que los oprime", así como incidir en la autonomía étnica. Estos lineamientos se recogieron en las Declaraciones de Barbados I (1971) y Barbados II (1977), y permiten reinterpretar la relación que había existido hasta entonces entre los pueblos indígenas y el concepto del desarrollo.

Fruto de estos encuentros y del establecimiento de nuevos lineamientos, los/ las antropólogos/ as desempeñaron un papel clave en la redefinición y planteamientos alternativos como es el caso del "etnodesarrollo". Tal y como recoge Pablo 
Palenzuela, este concepto fue elaborado por una comisión de intelectuales y dirigentes indígenas latinoamericanos en la reunión de San José de Costa Rica de 1981, y fue sistematizada posteriormente por el antropólogo mexicano Guillermo Bonfil Batalla quien lo define como el "proceso de transformación social sustentado por la capacidad social de un pueblo para construir su futuro, aprovechando para ello las enseñanzas de su experiencia histórica y los recursos reales y potenciales de su cultura, de acuerdo con un proyecto que se defina según sus propios valores y aspiraciones" (Bonfil Batalla, 1982: 133).

El etnodesarrollo surge como alternativa al modelo hegemónico del desarrollo y sitúa de forma expresa "los recursos reales y potenciales" de sus poblaciones, en el nivel local, contextualizándolos y vinculándolos a las necesidades, los deseos, las especificidades culturales y la participación activa de los grupos étnicos mismos. En este sentido, Palenzuela nos recuerda que no se trata de una propuesta culturalista, sino política porque dirige sus objetivos a transformar la correlación de fuerzas sobre la que se sostiene la jerarquización interétnica (Palenzuela, 2009: 137-138). Del mismo modo, dirige sus actuaciones a reconocer y poner en valor el nivel de conciencia de la identidad étnica, que se traduzca en la soberanía del grupo étnico para tomar decisiones que afectan a su desarrollo decidido "desde dentro".

\section{Presentación del monográfico}

Los trabajos que se presentan en este monográfico se han centrado, de una manera u otra, en los elementos que caracterizan la relación de la interculturalidad con el desarrollo y/ o etnodesarrollo como propuesta latinoamericana. Así por ejemplo, el texto de Alcida Ramos ha prestado atención a la manera en que la interculturalidad y el desarrollo se conectan, y el papel que puede desempeñar la antropología en este juego de imágenes distorsionadas que se devuelven entre los actores implicados en el proceso. A partir del análisis etnográfico de varios proyectos de desarrollo en la Amazonía Brasileña, Ramos reivindica una antropología cuyo papel fundamental es cuestionar la validez universal de categorías como desarrollo o interculturalidad, y su necesaria vinculación con temas frecuentemente postergados como el conocimiento indígena y los habituales problemas de entendimiento mutuo en el mundo interétnico de la Amazonia. La autora denuncia la falta de implicación, de interés de Occidente por esforzarse en entender profundamente las realidades desconocidas, dentro y fuera de él mismo, lo que combinado con el desequilibrio geopolítico de poder, ha sido una de las fuentes de sufrimiento más dañinas para los pueblos indígenas. Ramos señala en su trabajo que la interculturalidad puede constituir más una barrera que un mecanismo efectivo de comunicación, mientras que ésta no parta del principio de que cada parte implicada tenga un acceso igual a los recursos lingüísticos, simbólicos y materiales de todas las otras partes implicadas. Difícilmente podemos hablar de planteamientos, educación, ciudades o relaciones interculturales cuando solo uno de los grupos étnicos implicados (por ejemplo, grupos indígenas kichwas, aymaras, waoranis...) es el que habla los idiomas de todos los demás, mientras que por ejemplo, el grupo dominante (por ejemplo, grupo blanco-mestizo) sólo habla su lengua. La autora afirma que la interculturalidad sólo 
será intercultural cuando promueva el "ecumenismo de ideas y prácticas sobre el bien común", dejando a un lado promesas políticas que no siempre son étnicamente apropiadas y justas.

En esta misma línea se encuentra el trabajo planteado por Claudia Puerta para el caso de Colombia. En su trabajo, la autora entiende los proyectos de desarrollo como espacios relacionales, en los que la interculturalidad operaría como un régimen de alteridad — de modos de vida, identificaciones, espacios vitales, relaciones socioambientales, visiones del desarrollo-. Pero advierte ámbitos en los que la etnicidad es esencializada, lo que actúa como un importante obstáculo para la interculturalidad, para reconocer al Otro y su alteridad. Para esta autora, el desarrollo opera por norma general desconociendo las múltiples alteridades que caracterizan sus contextos de intervención. De esta manera, la autora afirma que comprender la interculturalidad en el desarrollo no consiste solamente en reconocer la diversidad cultural en términos étnicos, sino, y cada vez más, en las alteridades fundamentadas en cosmovisiones y relaciones socioambientales locales autóctonas dentro de una misma configuración sociocultural. A partir del concepto de "configuración sociocultural", va a desplazar el foco analítico hacia los "espacios vitales" y los regímenes de sentido, en lugar de centrarse exclusivamente en los rasgos y prácticas de los individuos. Todas estas categorías analíticas van a ser más útil para captar, describir y comprender los cambios culturales desde la perspectiva de los actores mismos. De esta manera, uno de los elementos que más se destacan en las reivindicaciones y demandas étnicas es la relación territorial con el modo de vida de vida propio, es decir, la defensa de la reproducción de espacios de vida diferenciales de la mismidad occidental. Pero los derechos reconocidos, y su gestión, nos dice Puerta, encuentran límites en las agendas económicas materializadas en los proyectos de desarrollo. De esta manera, se permite la reivindicación de los derechos culturales, sociales e incluso territoriales, pero los económicos son negados o desconocidos cuando son opuestos a los proyectos del desarrollo. La tensión básica entonces, no se encuentra tanto en las políticas de reconocimiento sino en las políticas de redistribución. Por ello, la regulación actual no tiene respuesta cuando las reivindicaciones de "Otros occidentales" apelan a la diferencia cultural y a sus derechos a la diferencia. Piden redistribución pero también autonomía en el tipo de desarrollo que quieren en sus espacios de vida.

El texto de Alejandro Isla analiza precisamente, desde un estudio de caso en el noroeste argentino, la implicación de la antropología aplicada a proyectos de desarrollo promovidos desde el Estado argentino en comunidades rurales. Con una amplia experiencia como antropólogo aplicado, el autor reflexiona sobre los diferentes roles que tuvo que asumir como consultor sobre políticas públicas, y señala tres aspectos clave en todo trabajo antropológico aplicado. El primero de ellos se relacionaría con la necesidad de ampliar el horizonte formativo de todos/ as aquellos/ as que quieran trabajar como antropólogos en el desarrollo. El autor se refiere a la enorme versatilidad que implica trabajar en el ámbito de la cooperación y en la necesidad de comprender Otros lenguajes técnicos, guiados por Otras lógicas disciplinares (agronomía, derecho, geografía, economía...). Por este motivo, el 
autor apuesta por la solidez teórica-metodológica en la formación disciplinar del antropólogo/a que complete su formación y que le haga dialogar con otras disciplinas. Uno de los aspectos más destacados por el autor, es el hecho de que el/ la antropólogo/a debe afrontar su trabajo en el ámbito del desarrollo en un terreno cambiante y sinuoso, modelado por los conflictos y las tensiones de poder. El autor concluye, que además de los análisis sobre la política local, se hace imprescindible identificar las dimensiones éticas del trabajo a desempeñar. En este sentido, el autor invita a trascender la identificación de las tradiciones antropológicas metropolitanas con el colonialismo. Sin negar el papel que estas tradiciones desempeñaron, el autor señala otros responsables como las élites republicanas americanas que se encontraban inmersas en la ideología de civilización eurocéntrica y genocida. Esos valores impregnan el sentido común de la sociedad donde el antropólogo nativo se ha criado, socializado y educado; por lo que constituye un ejercicio heurístico indispensable de la antropología sumergirse en ese sentido común para bucear y desenmascarar esos valores con ayuda de la teoría crítica.

Otro de los obstáculos más importantes para una efectiva implementación de la interculturalidad, es el mantenimiento de viejas lógicas políticas y culturales vinculadas al régimen de la hacienda en los contextos en los que se llevan a cabo programas y proyectos de desarrollo. Esto explicaría cómo a pesar de la larga trayectoria en materia de cooperación para el desarrollo, regiones enteras de América Latina no hayan conseguido transformar sus indicadores de desarrollo humano. Luis Alberto Tuaza identifica en su trabajo que uno de los factores explicativos del fracaso de la cooperación en la provincia de Chimborazo ha sido la falta de desarticulación de las prácticas clientelares de liderazgo político heredadas del régimen hacendatario, orientadas a dividir a las comunidades para conseguir el control político de las mismas. De esta manera, los proyectos de desarrollo estarían reforzando este tipo de liderazgos al incorporar en los proyectos a los "herederos" de ese viejo régimen, convertidos en los contextos de desarrollo en mediadores entre los proyectos y las comunidades. Así, aunque el régimen de la hacienda haya sido abolido en el Ecuador hace ya cinco décadas, se han mantenido prácticas clientelares vinculadas a liderazgos políticos, enmarcadas en las jerarquías étnicas establecidas por el sistema hacendatario. Esta lógica enmarcada claramente en la colonialidad del poder, es la que impide una efectiva implementación del desarrollo a través de sus proyectos.

Por su parte, Fernando García va a analizar en su trabajo la evolución de los estudios agrarios y étnicos en Ecuador en los últimos cincuenta años. A lo largo de su texto, el autor mostrará que ambos campos de estudio y sus actores, no solo siguen vigentes en el país, sino que ambos muestran diferentes intersecciones que han permitido que muchos cabos sueltos se aten y otros en cambio continúen todavía sueltos. Para ello, el autor se va a basar en los aportes llevados a cabo por la antropología ecuatoriana, sin dejar de lado el aporte hecho a la discusión desde las otras disciplinas de las ciencias sociales. Entre los cabos sueltos señalados por García, destacamos el racismo como uno de los obstáculos más importantes para conseguir la concreción de la interculturalidad como proyecto nacional y para el disfrute de los derechos humanos de los sectores históricamente discriminados como los indígenas 
y los afrodescendientes. A partir del año 2008, el Ecuador se ha definido como un Estado de derecho, plurinacional e intercultural, pero la discriminación racial y la exclusión étnica cultural hacia los indígenas y los afrodescendientes es todavía una práctica cotidiana de la población blanca y mestiza, tanto en el sector rural como en el sector urbano.

En este número, por tanto, nos interesa explorar cómo la antropología ha contribuido y contribuye a desnaturalizar y problematizar modelos identitarios y culturales hegemónicos propagados por el desarrollo en Latinoamérica. Estos análisis implican importantes desafíos para la antropología en sí misma, como el reconocimiento de "otras" antropologías que cuestionan y dialogan entre ellas desde una pluralidad de posiciones y de relaciones de poder que subyacen a las anteriores. En este sentido, más que celebrar la diversidad epistémica y étnica de Latinoamérica, se trata de situar en el centro de los análisis y reflexiones antropológicas, la problematización de los mecanismos del desarrollo que han contribuido a reforzar y se han apoyado en unas políticas identitarias en detrimento de otras conceptualizaciones y cosmovisiones.

\section{Referencias bibliográficas}

BONFIL, Guillermo

1978 "Los pueblos indios: viejos problemas, nuevas demandas en Mexico" en E. Valencia et al., Campesinado e Indigenismo en América Latina, Lima: Celats.

1982 "El etnodesarrollo, sus premisas jurídicas, políticas y de organización" en Rojas, F. (Ed.) América Latina: etnodesarrollo y etnicidio, San Jose (Costa Rica): Ediciones FLACSO, 131-145.

BRETÓN, Víctor; LÓPEZ BARGADOS; ROCA, Alberto

2005 "Las ONG en la reflexión antropológica sobre el desarrollo y viceversa: introducción" en Bretón, V., López Bargados, A., Las ONG en la reflexión antropológica sobre el desarrollo y viceversa. Perspectivas africanas y latinoamericanas, Sevilla: Fundación El Monte, Federación de Asociaciones de Antropología del Estado Español y Asociación Andaluza de Antropología, 9-21.

CASTRO-GÓMEZ, Santiago; GROSFOGUEL, Ramón

2007 "Prólogo. Giro decolonial, teoría crítica y pensamiento heterárquico" en S. CastroGómez y R. Grosfoguel (Eds.), El giro decolonial. Reflexiones para una diversidad epistémica más allá del capitalismo global. Bogotá: Iesco-Pensar-Siglo del Hombre Editores, 9-23.

CASTRO-GÓMEZ, Santiago

2007 "Decolonizar la universidad. La hybris del punto cero y el diálogo de saberes" en S. Castro-Gómez y R. Grosfoguel (Eds.), El giro decolonial. Reflexiones para una diversidad epistémica más allá del capitalismo global. Bogotá: Iesco-Pensar-Siglo del Hombre Editores, 79-91.

CÉSAIRE, Aimé

2006 [1955] Discurso sobre el colonialismo, Madrid: Akal. 
ESCOBAR, Arturo

1996 La invención del Tercer Mundo. Construcción y Deconstrucción del desarrollo, Bogotá: Norma.

1997 “Anthropology and Development”, International Social Science Journal, 154: 497-516.

2003 "Mundos y conocimientos de otro modo: El programa de investigación de Modernidad/colonialidad Latinoamericano", Tabula Rasa. (1): 51-86.

2012 "Más allá del desarrollo: postdesarrollo y transiciones del pluriverso", Revista de Antropología Social, volumen 21, Madrid: Universidad Complutense de Madrid.

ESTEVA, Gustavo

1996 "Desarrollo" en W. Sachs (Ed.) Diccionario del Desarrollo. Una guía del conocimiento como poder, PRATEC, Proyecto Andino de Tecnologías Campesinas.

FABIAN, Johannes

1983 Time and the Other. How Anthropology Makes its Object, Nueva York: Columbia University Press.

GIMENO, Juan Carlos; MONREAL, Pilar

1999 La controversia del desarrollo. Críticas desde la antropología, Madrid: Los Libros de la Catarata.

GIDDENS, Anthony

1993 Consecuencias de la modernidad, Madrid: Alianza Universidad.

GLEDHILL, John

2000. El poder y sus disfraces, Barcelona: Bellaterra.

GRONEMEYER, Marianne

1996 “Ayuda” en W. Sachs (Ed.), Diccionario del Desarrollo. Una guía del conocimiento como poder, PRATEC, Proyecto Andino de Tecnologías Campesinas.

GROSFOGUEL, Ramón

2006 "La descolonización de la economía política y los estudios postcoloniales. Transmodernidad, pensamiento fronterizo y colonialidad global". Tabula Rasa. (4): $17-48$.

GUERRERO, Andrés

2000 "El proceso de identificación: sentido común ciudadano, ventriloquia y transescritura". En A. Guerrero (Comp.), Etnicidades, Quito: FLACSO.

2010 Administración de poblaciones, ventriloquias y transescritura. Lima: Instituto de Estudios Peruanos-FLACSO Ecuador.

HANSEN, Thomas; STEPPUTAT, Finn

2001 "Introduction: States of Imagination" en T. Hansen y F. Stepputat (Eds.) States of Imagination. Ethnographic Explorations of the Postcolonial State, Durham: Duke University Press.

HARRIS, Marvin

2000 Teorías sobre la cultura en la era posmoderna, Barcelona: Crítica. 
LANDER, Edgardo (Ed.)

2000 La colonialidad del saber: eurocentrismo y ciencias sociales. Perspectivas Latinoamericanas, Buenos Aires: CLACSO, Consejo Latinoamericano de Ciencias Sociales.

LATOUCHE, Serge

2007 Sobrevivir al desarrollo, Barcelona: Icaria.

LINS RIBEIRO, Gustavo; ESCOBAR, Arturo

2008 Antropologías del mundo: transformaciones disciplinarias dentro de sistemas de poder, Popayán: Wenner-Gren Foundation for Anthropological Research, Envión Editores y CIESAS.

MALDONADO-TORRES, Nelson

2007 "Sobre la colonialidad del ser: contribuciones al desarrollo de un concepto" en S. Castro-Gómez y R. Grosfoguel (Eds.), El giro decolonial. Reflexiones para una diversidad epistémica más allá del capitalismo global. Bogotá: Iesco-Pensar-Siglo del Hombre Editores, 127-167.

MARÍN, Isabel

2004 "Emigración, pobreza y cooperación al desarrollo en el Norte de Marruecos: discursos y realidades entre las dos orillas", Girona: Actas del $4^{\circ}$ Congreso sobre la inmigración en España.

MARZAL, Manuel

1998 Historia de la Antropología. Volumen I, Antropología Indigenista. Quito: Abya Yala y Universidad Politécnica Salesiana.

MIGNOLO, Walter

2002 "Geopolitics of knowledge and colonial difference", The South Atlantic Quarterly 101 (2): 57-96.

2003 “Un paradigma otro': colonialidad global, pensamiento fronterizo y cosmopolitismo crítico". En W. Mignolo, Historias locales-diseños globales: colonialidad, conocimientos subalternos y pensamiento fronterizo, Madrid: Akal, 19-60.

MONTÚFAR, César

2002 Hacia una teoría de la asistencia internacional para el desarrollo. Un análisis desde su retórica, Quito: Centro Andino de Estudios Internacionales, Universidad Andina Simón Bolívar y Corporación Editora Nacional.

PALENZUELA, Pablo

2009 "Mitificación del desarrollo y mistificación de la cultura: el etnodesarrollo como alternativa", Íconos. Revista de Ciencias Sociales, Num. 33, Quito: FLACSOEcuador, 127-140.

PICAS, Joan

2001 El papel de las Organizaciones No Gubernamentales y la crisis del desarrollo. Una crítica antropológica a las formas de cooperación. Tesis Doctoral, inédita, Barcelona: Universidad de Barcelona. 
PUJADAS, Juan José

2011 "Los claroscuros de la etnicidad. El culturalismo evaluado desde la óptica de la cohesión social y la ciudadanía” en P. Palenzuela y A. Olivi (Coords.) Etnicidad y Desarrollo en los Andes, Sevilla: Universidad de Sevilla,, 25-52.

QUIJANO, Aníbal

2000a "Colonialidad del poder y clasificación social". Journal of World-System Research. (2): 342-386.

2000b “Colonialidad del poder, eurocentrismo y América Latina” en Edgardo Lander (Ed.), La Colonialidad del saber: Eurocentrismo y Ciencias Sociales. Perspectivas Latinoamericanas. Caracas: Clacso, 201-245

\section{RIBEIRO, Darcy}

1977 As Américas e a Civilização - Processo de Formação e Causas do Desenvolvimento Cultural Desigual dos Povos Americanos, Petrópolis: Editora Vozes.

RIST, Gilbert

2002 El desarrollo: historia de una creencia occidental, Madrid: Los Libros de La Catarata.

ROBERTSON, Alexander Foster

1984 People and the State. An Anthropology of Planned Development, Cambridge: Cambridge University Press.

SAMPEDRO, Jose Luis; BERZOSA, Carlos

1996 Conciencia del subdesarrollo veinticinco años después, Madrid: Taurus.

UNCETA, Koldo

2009 "Desarrollo, subdesarrollo, maldesarrollo y postdesarrollo: una mirada transdisciplinar sobre el debate y sus implicaciones", Carta Latinoamericana, $\mathrm{n}^{\mathrm{0}} 7$, Montevideo.

VARESE, Stefano

1971 “Consideraciones de Antropología Utópica”, Textual, Lima: Instituto Nacional de Cultura.

WALSH, Catherine

2002 “(De)construir la Interculturalidad. Consideraciones críticas desde la política, la colonialidad y los movimientos indígenas y negros en el Ecuador”. En Fuller, N. Interculturalidad y Política. Desafios y Posibilidades. Perú: Red para el Desarrollo de las Ciencias Sociales: 115-142.

2005 “(Re)pensamiento crítico y (de)colonialidad”. En C. Walsh (Ed.), Pensamiento crítico y matriz (de)colonial. Reflexiones latinoamericanas. Quito: Universidad Andina Simón Bolívar-Abya-Yala, 13-35.

2006 "Interculturalidad y (de)colonialidad: diferencia y nación de otro modo". En: Desarrollo e interculturalidad, imaginario y diferencia: la nación en el mundo Andino. Quito: Académica de la Latinidad, 27-43. 


\section{ZÚÑIGA, Xenia}

2011 "La interculturalidad como relación imaginada y práctica social: experiencias con y desde los pueblos indígenas en América Latina", Cuadernos Inter.c.a.mbio sobre Centroamérica y el Caribe, Año 8, nº 9, 85-103. 